\title{
Penerapan Aplikasi Android Pengenalan Huruf Hijaiyah Metode Waterfall Pada Paud Al Fina
}

\author{
Feri Prasetyo ${ }^{[1]^{*}}$, Agus Dendi ${ }^{[2]}$, Jumadi Nur ${ }^{[3]}$ Faisal Adam ${ }^{[4]}$ \\ Program Studi Sistem Informasi, Universitas Bina Sarana Informatika ${ }^{[1],[3],[4]}$ \\ Program Studi Sistem Informasi, ISB Atma Luhur ${ }^{[2]}$ \\ Jl Kramat Raya Nomor 98 Senen Jakarta Pusat ${ }^{[1],[3],[4]}$ \\ Jl. Jend. Sudirman, Kel. Selindung, Kec.Gabek Pangkalpinang ${ }^{[2]}$ \\ feri.fpo@bsi.ac.id ${ }^{[1]}$,dendi@atmaluhur.ac.id ${ }^{[2]}$.jumadi1021@bsi.ac.id ${ }^{[3]}$, Faisal1102@bsi.ac.id
}

\begin{abstract}
Recognition and mastery of the hijaiyah letters which are the basis for reading and studying the Holy Qur'an from an early age is very important, because if at the time of reading the hijaiyah letters you are accustomed to the wrong words it will cause different meanings so that we are required to read properly and correctly. The method in learning hijaiyah letters is usually given by traditional (conventional) reciting teachers or people often call it the sequential method. With this kind of teaching, children tend to be passive in accepting their teaching lessons, because the Koran teacher explains the children in learning to read hijaiyah letters orally, in writing and in body language. The application of recognizing hijaiyah letters is very effective and easy to use for students of paud al fina in recognizing and writing hijaiyah letters because the design of the learning aid program to read hijaiyah letters is a method in the form of visualization in the form of images, text and sound. To implement this method, the author uses Android Studio programming which acts as a tool (programming system) used to build an application, this application program is expected to generate interest for early childhood or adults who want to learn how to learn to read hijaiyah letters properly and correctly. accommodated.
\end{abstract}

Keywords-Hijaiyah, Android Studio 3.1.2

Abstrak-Abstrak Pengenalan dan penguasaan huruf hijaiyah yang merupakan dasar untuk membaca dan mempelajari kitab suci Al-Qur'an sejak dini sangat penting, karena jika pada saat membaca huruf hijaiyah sudah terbiasa dengan kata-kata yang salah maka akan dapat menimbulkan arti yang berbeda sehingga kita dituntut untuk membaca secara baik dan benar. Metode dalam belajar huruf hijaiyah biasanya diberikan oleh guru mengaji secara tradisional (konvensional) atau orang sering menyebutnya dengan metode turutan. Dengan pengajaran seperti ini anak cenderung pasif dalam menerima pelajaran mengajinya, karena guru mengaji menerangkan anak dalam belajar membaca huruf hijaiyah secara lisan, tulisan dan bahasa tubuh. dengan Aplikasi mengenal huruf hijaiyah sangat efektif dan mudah di gunakan untuk siswa paud al fina dalam mengenal dan menulis huruf hijaiyah karena desain program bantu belajar membaca huruf hijaiyah dengan metode dalam bentuk visualisasi yang berupa gambar, teks dan suara. Untuk mengimplementasikan metode tersebut Penulis menggunakan pemrograman Android Studio yang berperan sebagai alat (sistem pemrograman) yang digunakan untuk membangun sebuah aplikasi, program aplikasi ini diharapkan menimbulkan minat bagi anak usia dini atau orang dewasa yang ingin mempelajari cara belajar membaca huruf hijaiyah secara baik dan benar dapat diakomodasi.

\section{Kata Kunci-Hijaiyah, Membaca, Android Studio 3.1.2}

\section{PENDAHULUAN}

Sistem pembelajaran pada PAUD Alfina dalam mengenal huruf hijaiyah masih menggunakan metode pembelajaran deskriptif yaitu pengajar memberikan cerita kemuadi meberikan penjelasan materi pembelajaran dan memberikan catatan-catatan untuk dihapal para murid lalu dikuti oleh murid. Metode seperti ini sering sekali dilakukan oleh seorang guru kepada murid. Namun permasalahanya Sedangkan setiap murid berbeda-beda terutama dalam menyerap pembelajaran yang diberikan pengajar. Di Paud Al-Fina banyak siswa yang sulit untuk mengingat dan menhafal huruf hijaiyah masalah seperti begitu pula cara membacanya karna siswa harus ada pembimbing dalam membacanya, untuk itu perlu dibuatkan suatu metode agar siswa tersebut dapat memahami dengan mudah, oleh sebab tersebut perlu di buatkan sistem yang mudah untuk di gunakan siswa Paud Al fina. Suatu sistem merupakan jaringan kerja dari prosedur - prosedur dimana saling terikat, menyatu bersama-sama untuk melakukan suatu proses atau menyelesaikan suatu sasaran tertentu" [1] dari sitem inilah yang nantikan akan di gunakan siswa paud dalam menghafal huruf hijaiyah.

Kondisi Saat ini sangat diperlukan Media pembelajaran mobile dimana tampilan bentuk visual yang sangat menarik dan memberikan banyak manfaat untuk kepentingan dalam dunia pendidikan terutama anak Paud. Pemakaian aplikasi mobile pembelajaran dalam proses mengajar juga membangkitkan motivasi belajar dan membawa pengaruh psikologi terhadap anak didik, dengan adanya aplikasi mobile dapat dimanfaatkan oleh anak paud dengan penggunaan android, Kelebihan android di banding sistemn operasi yang lain bersifat opensouce code sehingga memudahkan para pengembang untuk menciptakan modifikasi fitur di sistem operasi android sesuai keinginan sendiri [2].

Dengan mengunakan android dapat di gunakan sebagai alat dalam proses pembelajaran yang interaktif karena lebih 
menyenangkan dimana pembelajaran adalah gabungan dari beberapa unsur yaitu teks, gambar, audio, video dan animasi, sehingga dapat lebih efektif dan efisien dalam kegiatan belajar. Penelitian sebelumnya , "aplikasi metode pembelajaran mengenal huruf hijaiyah untuk anak usia2-3 bisa digunakan sebagai metode alternatif dalam mendukung cara memahami belajar anak sambil bermain sekaligus dapat melatih motorik anak dan melatih memori anak" [3].

Penggunaan Aplikasi android dapat mempermudah anak usia dini dalam mengenal dan memahami tentang huruf hijaiyah yang bertipe visual dimana mereka bisa lebih memahami huruf hijaiyah dan harokat dengan gambaran yang jelas". [4] Selain itu Hasil analisa pada aplikasi huruf hijaiyah berbasis android, siswa menjadi tertarik belajar dan mudah untuk belajar membaca dan menulis huruf hijaiyah di Taman Baca Al Quran Raziev Reinezhwa Banjarmasin [5], Selain tingkat Paud pada tinggkat sekolah menengah atas Android juga di gunakan pada Materi Kelarutan media pembelajaran lewat android Android dapat memberikan pengaruh pada nilai peningkatan performa akademik berupa motivasi untuk belajar dan hasil belajar kognitif peserta didik di SMA [6] Selain itu pengunakan pembeljaran lewat android di temukan keefektifan hasil belajar siswa dengan menggunakan media pembelajaran android pada mata kuliah biologi dibandingkan dengan menggunakan pembelajaran cermah. hal ini ini terjadi karena pembelajaran dengan menggunakan media pembelajaran dapat dimana saja dan kapan saja. [7] pada tingkat perguruan tinggi pengunaan aplikasi android digunakan dalam sistem informasi akademik di Unisma menghasilkan sistem informasi akademik yang menggunakan basis Android memiliki keuntungan yaitu dapat diakses melalui Handphone android untuk Komunikasi jarak jauh dengan banyak kemudahan, kepusan pengguna sistem dan kecepatan informasinya. [8]

Oleh sebab itu, pada kegiatan penelitian ini penulis mencoba mencari solusi untuk membuat aplikasi mobile pengenalan huruf hijaiyah berbasis android. Dengan adanya aplikasi mobile ini mempermudah bagi anak anak

\section{LANDASAN TEORI}

\section{A. Android}

Android merupakan aplikasi open source yang bisa dikatakan komprehensif dan dirancang untuk perangkat mobile dengan konten komprehensif dimana pada aplikasi berbasis android menyediakan frameworks, inilah yang dapat di terapkan untuk pengembangan aplikasi pada suatu perangkat mobile.

Android Studio adalah sebuah Tampilan yang bisa diterapkan untuk pengembangan aplikasi Android, dan dikembangkan oleh Google. Android Studio merupakan pengembangkan dari Eclipse IDE, dan dibuat berdasarkan IDE Java populer, yaitu IntelliJ IDEA. Android menyediakan platform yang terbuka bagi para pengembang untuk menciptakan aplikasi sendiri [9].

\section{B. Java}

Java dikembangkan oleh perusahaan Sun Microsystem. [6] "Java menurut definisi dari Sun Microsystem adalah nama untuk sekumpulan teknologi untuk membuat dan menjalankan perangkat lunak pada komputer stand alone ataupun pada lingkungan jaringan" [10].

Java merupakan " sebuah teknologi yang di perkenalkan oleh Sun Microsystems pada pertengahan tahun 1990 nama untuk sekumpulan teknologi yang di gunakan untuk membuat dan menjalankan perangkat lunak pada komputer standlone ataupun pada lingkungan jaringan”. [11]

\section{Audacity}

Dalam pembuatan aplikasi pengenalan huruf hijaiyah ini, digunakan aplikasi audacity untuk memberi dan menambahkan konsep efek suara pada aplikasi tersebut, dari pengertian tersebut diatas dapat disimpulkan bahwa audacity dapat di katakana sebuah aplikasi yang digunakan untuk merekam dan mengedit suara. Audacity juga aplikasi yang gratis dan open source.

\section{UML (Unfied Modeling Languange)}

"UML (Unified Modelling Language) adalah bahasa pemodelan untuk sistem atau perangkat lunak yang berparadigma berorientasi objek. Pemodelan (modelling) sesungguhnya digunakan penyederhanaan permasalahan permasalahan yang kompleks sedemikian rupa sehingga lebih mudah dipelajari dan dipahami”[12].

\section{E. Sequence Diagram}

"Sequence diagram merupakan diagram yang menggambarkan kolaborasi yang dinamis antara objek satu dengan yang lain. Kolaborasi ini di tunjukan dengan adanya interaksi antar obyek di dalam dan di sekitar sistem yang berupa pesan atau instruksi yang berurutan" [13].

\section{F. Class Diagram}

"Class diagram yaitu salah satu jenis diagram pada UML yang di gunakan untuk menampilkan kelas-kelas maupun paket-paket yang ada pada suatu sistem yang nantinya akan di gunakan. Jadi, diagram ini dapat di memberikan sebuah gambaran mengenai sistem maupun relasi-relasi yang terdapat pada sistem tersebut". [14]

\section{G. Waterfall}

"Model SDLC air terjun waterfall sering juga di sebut model sekuensial linier (sequential linear) atau alur hidup klasik (classic life cycle). Model air terjun menyediakan pendekatan alur hidup perangkat lunak secara sekuensial atau terurut di mulai dari analisis, desain, pengodean, pengujian, dan tahap pendukung (support)" [15].

\section{METODE PENGEMBANGAN SISTEM}

\section{A. Metodologi}


Metodologi yang dipilih adalah metode pengembangan Sistem, dimana Pengembangan terhadap sistem menggunakan metode pendekatan waterfall, dipilih karena pendekatan ini memiliki cakupan serta struktur yang sangat jelas dan terarah dari alur setiap tahapan perancangan dan implementasinya

\section{1) Perencanaan}

Kegiastan ini berupa mengidentifikasi masalah, dan penentuan tujuan dari system yang di buat:

\section{a) Mengidentifikasi masalah}

Sistem pembelajaran masih mengunakan Teknik ceramah yang di lakukan oleh guru kemudian siswa mengikutinya dan penggunaan buku sebagai media belajarnya agar lebih interaktif dan mudah di pahami perlu dirancang aplikasi yang dapat membantu guru paud dalam pembelajaran menegenal huruf hijaiyah.

\section{b) Tujuan sistem pembelajaran}

Aplikasi huruf hijaiyah ini agar dapat di gunakan untuk membantu siswa dalam belajar tentang bagaimana cara membaca dan mengenal huruf hijaiyah agar mudah di ingat dan tidak membuat bosan.

\section{PERANCANGAN SISTEM}

Tahap perancangan sistem bertujuan untuk merancang pemodelan proses, dan antar muka pengguna (user interface) A. Pemodelan proses system belajar

Model system belajar sebagi berikut : a) Use Case Diagram

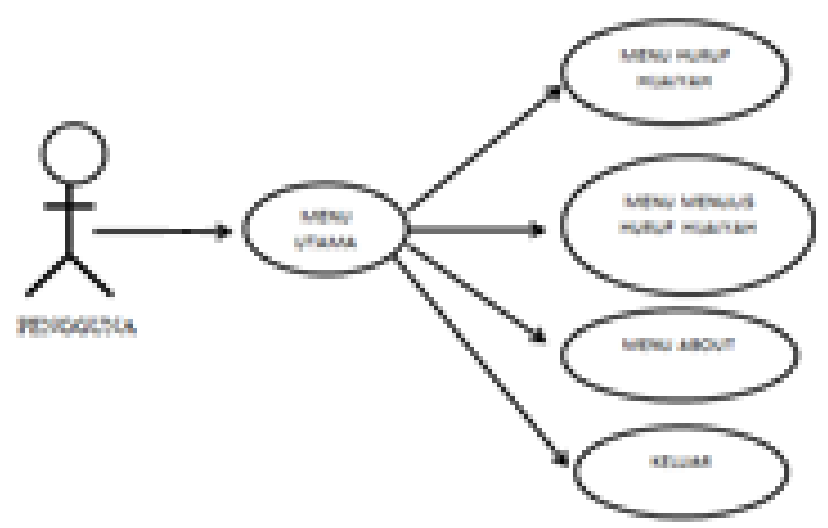

Gambar 1. Rancangan Diagram Use Case Menu Utama

Use Case merupakan pemodelan untuk kegiatan sistem informasi yang akan di buat dimana penguna dapat mengunakan aplikasi di dalam menu utama yang berisi menu huruf yang dapat digunakan untum melihat huruf apa saja yang dapat di gunakan, kemudian menu menulis dimana menu ini dapat di gunakan untuk menulis huruf, menu about dan keluar.
TABLE 1 IDENTIFIKASI MENU UTAMA

\begin{tabular}{|c|c|}
\hline \multicolumn{2}{|c|}{ Identifikasi } \\
\hline Nama Usecase & Menu Utama \\
\hline Aktor & Pengguna \\
\hline Tujuan & Pengmpilkan halaman Utama menjalan kan aplikasi \\
\hline Kondisi Awal & Skenario Utama \\
\hline Aktor & Sistem \\
\hline $\begin{array}{c}\text { 1. Menjalankan } \\
\text { Aplikasi }\end{array}$ & 3. Pilihan Menu utama \\
\hline & $\begin{array}{c}\text { Pengguna dapat melihat halaman menu } \\
\text { utama }\end{array}$ \\
\hline
\end{tabular}

Tabel di atas ada 2 proses dimana proses identifikasi dan ke dua scenario utama, kolom pertama pada tabel identifikasi diatas menjelaskan keterangan berupa nama uscase, aktor, tujuan sedangkan kolom ke dua menjelaskan kegiatanya bahwa aktor tersebut akan memproses menu utama di mana aktornya sebagai pengguna tujuanya membuka tampilan menu utama, dengan tujuan kondisi awal menjalankan apikasi menu utama. Saat membuka aplikasinya dan skenarionya utamanya berupa, aktor pertama membuka aplikasi, kemudian sistem akan memproses menampilkan menu utama, selanjutnya penguna akan melihat tampilan halaman menu utama di layar android

\section{b) Use Case Diagram Menu Belajar}

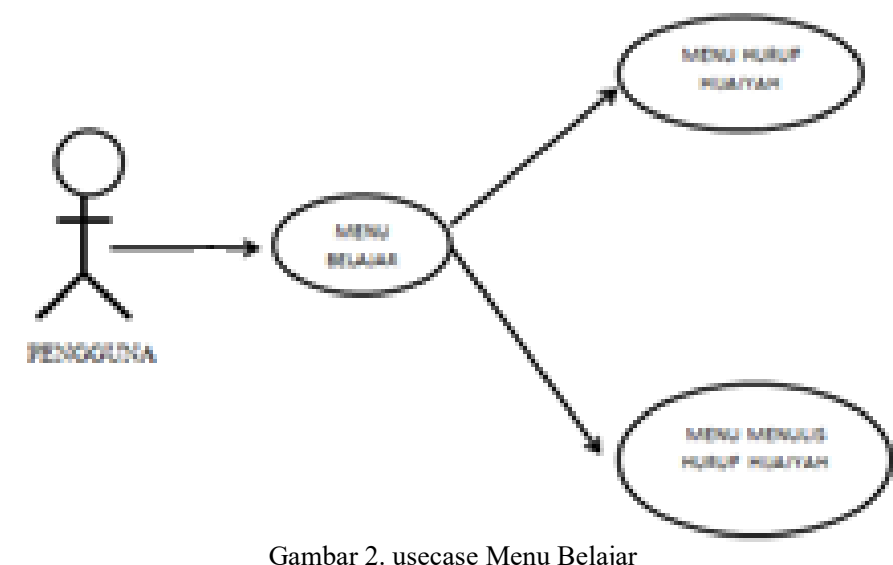

Menu belajar di gunakan untuk memulai belajar huruf dimana kontennya berisi menu huruf dan menu menulis huruf, sehingga pada proses ini siswa dapat melihat hurufnya kemudian di lanjutkan ke menu berikutnya untuk dapat menuliskannya kembali.

TABEL 2 IDENTIFIKASI MENU BELAJAR

\begin{tabular}{|c|c|}
\hline \multicolumn{2}{|c|}{ Identifikasi } \\
\hline Nama Usecase & Menu belajar \\
\hline Aktor & Pengguna \\
\hline Tujuan & Melihat halaman Menu Belajar \\
\hline Kondisi Awal & Menampikan halaman menu utama \\
\hline \multicolumn{2}{|c|}{ Skenario Utama } \\
\hline Aktor & Sistem \\
\hline 1. Menjalankan Aplikasi & 2. Menampilkan halaman menu belajar \\
\hline Kondisi akhir & menampilakn halaman menu belajar \\
\hline
\end{tabular}


Tabel di atas memiliki 2 proses dimana proses identifikasi dan ke dua skenario utama, kolom pertama berupa identifikasi menjelaskan keterangan berupa nama uscase, aktor, tujuan dan kondisi awal, sedangkan kolom ke dua menjelaskan kegiatanya bahwa aktor tersebut akan memproses menu belajar maka sistem akan menampilkan menu belajar, tujuanya membuka tampilan menu belajar, dengan tujuan kondisi awal menjalankan apikasi menu belajar. Proses Saat membuka aplikasinya dalam skenario utamanya berupa, aktor pertama membuka aplikasi menu belajar, kemudian sistem akan memproses menampilkan menu belajar, selanjutnya penguna akan melihat tampilan halaman menu belajar di layar android

\section{c) Use Case Diagram Huruf Hijaiyah}

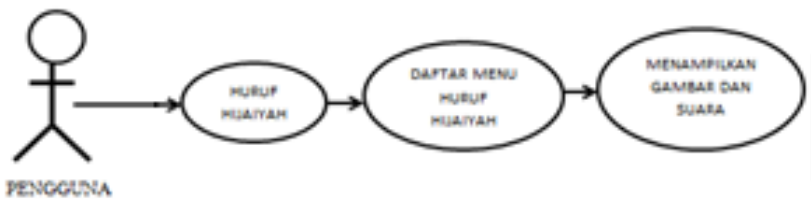

Gambar 3. Huruf Hijaiyah

Pada bagian ini pengguna dapat melihat daftar menu huruf apa saja yang akan di tampikan kemudian melihat gambar dan mendengarkan bagai mana pengucapan yang benar disertai suara dan ejaanya.

TABEL 3. IDENTIFIKASI MENU HURUF

\begin{tabular}{|c|c|}
\hline \multicolumn{2}{|r|}{ Identifikasi } \\
\hline Nama Usecase & Huruf Hijaiyah \\
\hline Aktor & Pengguna \\
\hline Tujuan & $\begin{array}{c}\text { Melihat gambar dan mendengar kan } \\
\text { huruf }\end{array}$ \\
\hline Kondisi Awal & menampilkan halaman menu belajar \\
\hline \multicolumn{2}{|c|}{ Skenario Utama } \\
\hline Aktor & Sistem \\
\hline $\begin{array}{l}\text { 1. Menjalankan } \\
\text { Aplikasi }\end{array}$ & $\begin{array}{l}\text { 2. Menampilkan halaman huruf } \\
\text { hijaiyah }\end{array}$ \\
\hline $\begin{array}{l}\text { 3. Mimilih salah satu } \\
\text { huruf }\end{array}$ & 4. Menampikna gambar dan suara \\
\hline Kondisi akhir & menampikan gambar dan suara \\
\hline
\end{tabular}

Tabel di atas memiliki 2 proses dimana proses identifikasi dan ke dua skenario utama, kolom pertama berupa identifikasi menjelaskan keterangan berupa nama uscase, aktor, tujuan dan kondisi awal, sedangkan kolom ke dua menjelaskan kegiatanya bahwa aktor tersebut akan memproses menu huruf maka sistem akan menampilkan menu huruf, tujuanya melihat dan menampilkan gambar dan huruf, dengan tujuan kondisi awal menjalankan apikasi menu belajar. Proses Saat membuka aplikasinya dalam skenario utamanya berupa, aktor pertama membuka aplikasi menu belajar, kemudian sistem akan memproses menampilkan menu huruf, dan memlikiuh salah satu huruf, selanjutnya penguna akan melihat tampilan halaman menu huruf dengan gambar dan suara di layar android.

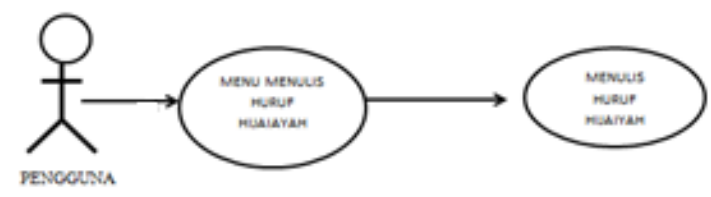

Gambar.4 Rancangan Diagram Use Case Menulis Huruf Hijaiyah

Gambar 4 Penguna dapat menggunakan menu menulis huruf, dimana dalam tampilan ini pengguna agar dapat menerapkan kembali huruf yang sudah di lihatnya dan menuliskanya kembali.

TABEL 4. IDENTIFIKASI MENULIS HURUF HIJAIYAH

\begin{tabular}{|c|c|}
\hline & Identifikasi \\
\hline Nama Usecase & Menulis huruf \\
\hline Aktor & Pengguna \\
\hline Tujuan & $\begin{array}{c}\text { menulis huruf hijaiyah } \\
\text { Kondajar }\end{array}$ \\
\hline \multicolumn{2}{|c|}{ Skenario Utama } \\
\hline Aktor & Sistem \\
\hline $\begin{array}{c}\text { 1. Memilih button } \\
\text { menulis huruf }\end{array}$ & $\begin{array}{c}\text { 2. Menampilkan halaman menulis } \\
\text { huruf hijaiyah }\end{array}$ \\
\hline $\begin{array}{c}\text { 3. Mimilih salah satu } \\
\text { huruf }\end{array}$ & 4. Menampikna gambar \\
\hline Kondisi akhir & menampikan gambar \\
\hline
\end{tabular}

Proses identifikasi dan ke dua skenario utama, kolom pertama berupa identifikasi menjelaskan keterangan berupa nama uscase, aktor, tujuan dan konsisi awal, sedangkan kolom ke dua menjelaskan kegiatanya bahwa aktor tersebut akan memproses menu menulis huruf maka system akan menampilkan menu menulis huruf, tujuanya menulis huruf huruf, dengan tujuan kondisi awal menampilakan halaman menu belajar. Proses Saat membuka aplikasinya dalam skenario utamanya berupa, aktor pertama membuka aplikasi dengan memilih button menuliskan huruf, kemudian sistem akan memproses menampilkan menu halaman menulis huruf, dan memilih salah satu huruf, selanjutnya sitem akan membawa penguna melihat tampilan gambar huruf yg telah di tulis di layar android

\section{e) Activity Diagram}

Pada gambar 4 langkah awal Memulai aplikasi, masuk ke munu utama, sistem akan menampilkan tampilan huruf hijaiyah, sistem akan menampilkan gambar dan suara, kemudian selesai

\section{d) Menulis huruf hijaiyah}




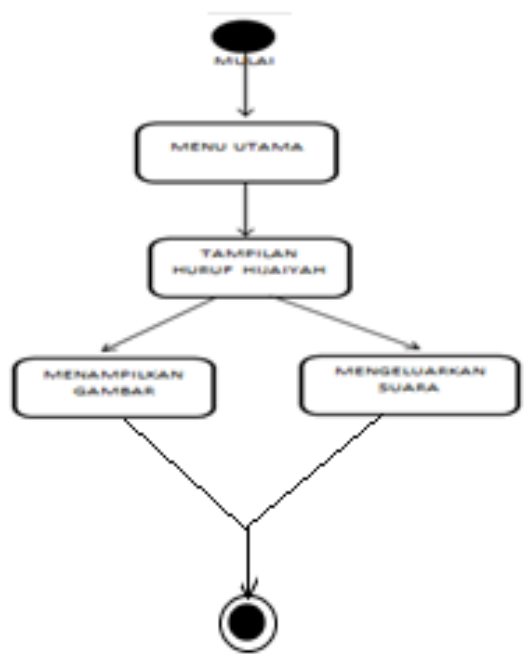

Gambar 4. Diagram Activity Huruf Hijaiyah

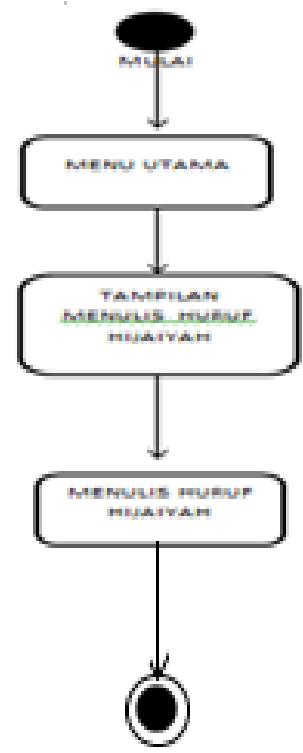

Gambar 5. Rancangan Diagram Activity Menulis Huruf Hijaiyah

Pada gambar 5 langkah awal Memulai aplikasi, penguna dapat masuk ke munu utama, kemudian akan tampil menulis huruf, sistem akan menampilkan tampilan menulis huruf hijaiyah, kemudian selesai

\section{f) Rancangan Antarmuka}

- Menu Utama

Pada tampilan Menu Utama aplikasi terdapat satu ImageView untuk menampilkan Judul dan Logo, serta terdapat tiga ImageButton yang terdiri dari Huruf hijaiyah, menulis huruf hijaiyah, about.

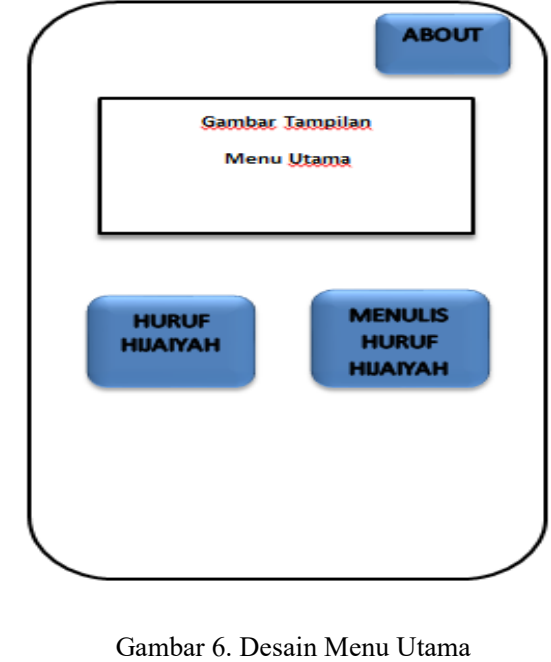

a. Gambar tampilan menu utama

Pada gambar tampilan menu utama berisi judul

b. Button huruf hijaiyah

Jika pengguna memilih button Huruf Hijaiyah maka akan masuk ke menu Huruf Hijaiyah.

c. Button Menulis Huruf Hijaiyah

Jika pengguna memilih Button Menulis Huruf Hijaiyah maka akan masuk ke menu Menulis Huruf Hijaiyah.

d. Button About

Jika pengguna memilih Button About maka akan masuk ke menu About atau tentang aplikasi huruf hijaiyah.

- Menu Huruf Hijaiyah

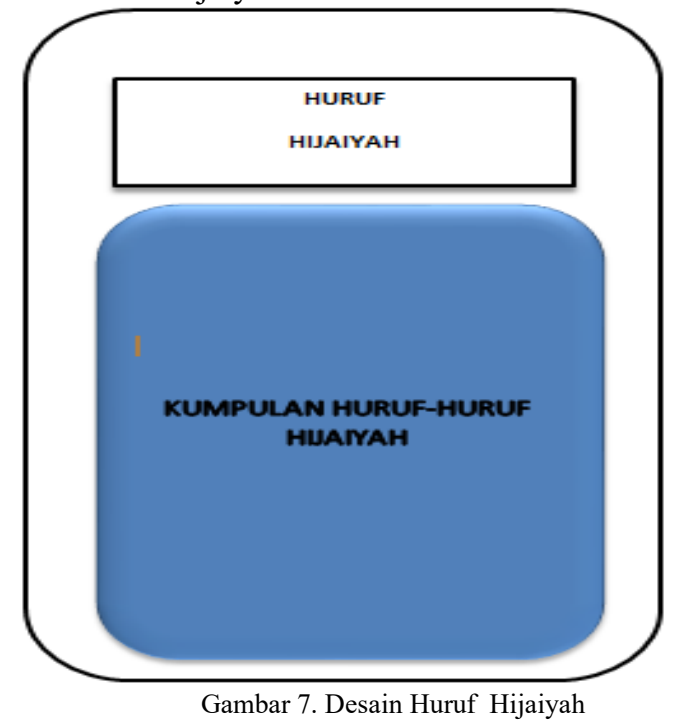

a. Huruf Hijaiyah

Pada Huruf Hijaiyah berisi tulisan Hururf Hijaiyah

b. Kumpulan Huruf-Huruf Hijiayah

Jika pengguna memilih kumpulan Huruf-huruf hijaiyah maka akan masuk ke menu Huruf 
Hijaiyah. Lalu bisa melihat gambar dan dapat pula mendengar suara

- $\quad$ Menu Menulis Huruf Hijaiyah

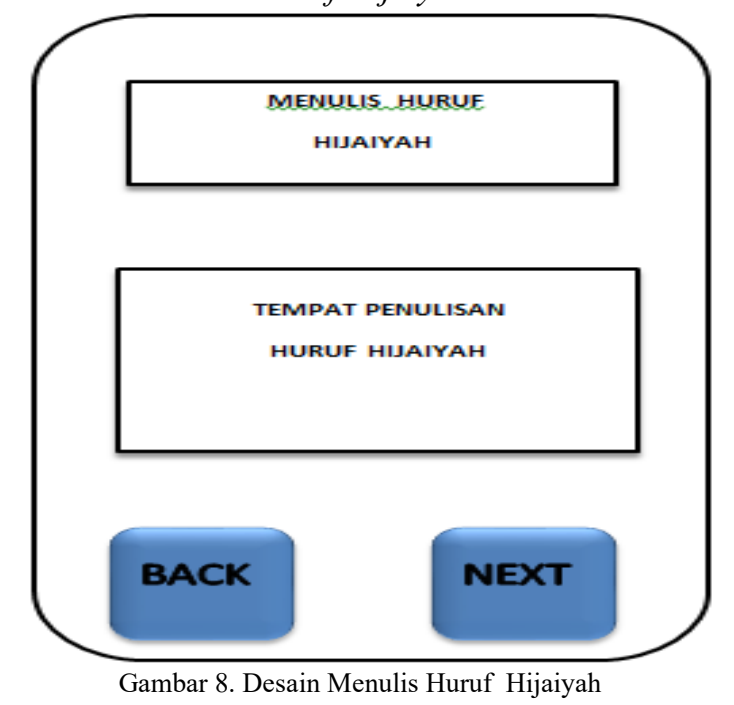

a. Menulis Huruf Hijaiyah

Pada Menulis Huruf Hijaiyah berisi judul dari menu tampilan menulis huruf Hijaiyah

b. Tempat Penulisan Huruf Hijaiyah pengguna dapat melakukan penulisan pada from tempat penulisan huruf hijaiyah

c. Button Back

Pengguna dapat kembali kemenu sebelumnya pada saat berada di form penulisan huruf hijaiyah.

d. Button Next

Pada Button Next Pengguna dapat melanjutkan menulis huruf berikutnya, jika sudah melakukan penulisan di form penulisan huruf hijaiyah

- Menu Tampilan About

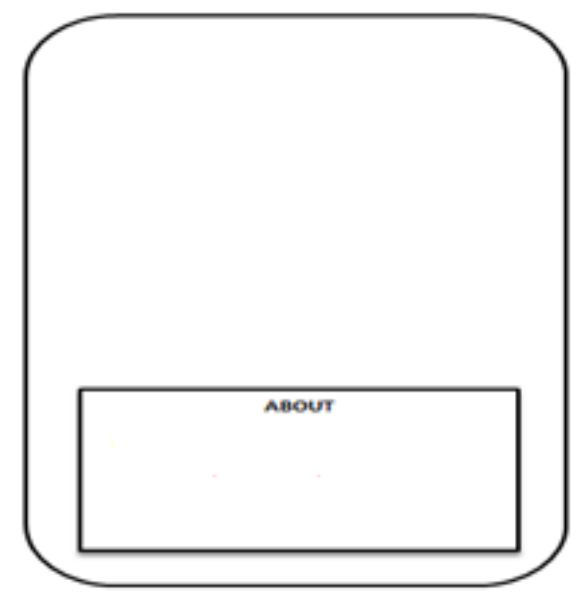

Gambar 9. About
Tampilan ini berisi keterangan pengunan aplikasi mengenal huruf hijaiyah

\section{PEMBAHASAN DAN HASIL}

Pada bab ini di dasari pada tahapan Analisa dan perancangan sistem yang berupa kebutuhan system pendukung untuk aplikasi mengenal huruf hijaiyah dalam tahapan implementasi dan pengujian system

\section{A. Implementasi menu utama}

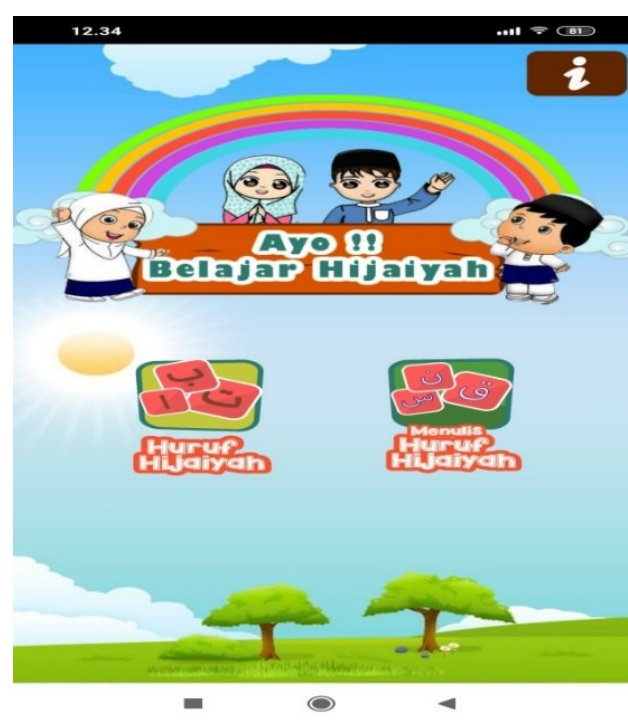

Gambar 10. Tampilan Menu Huruf Hijaiyah

Menu ini merupakan menu utama dan Tampilan ini terdapat tombol yang akan menampilkan huruf hijaiyah dan menampilkan menulis huruf hijaiyah

\subsection{Implementasi menu huruf hijaiyah}

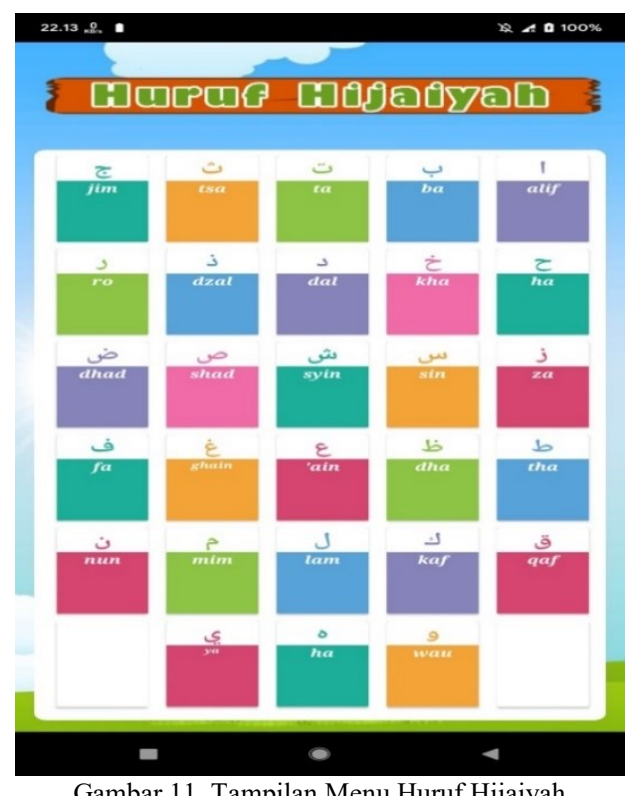

Gambar 11. Tampilan Menu Huruf Hijaiyah 
Pada gambar 11 sistem akan menampilkan huruf hijaiyah, dan ketika pengguna menekan salah satu huruf makan aplikasi akan menunjukan bentuk huruf disertai dengan suara cara pengucapannya.

\section{B. Implementasi menulis huruf}

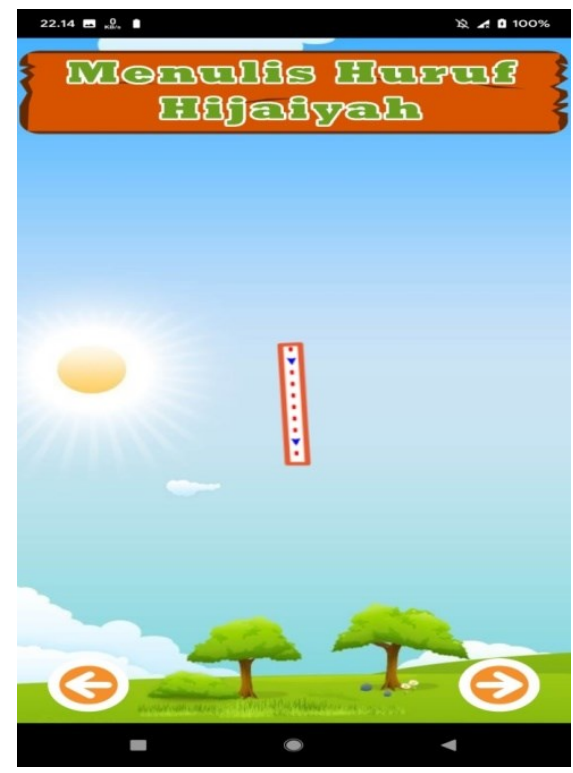

Gambar 12. Tampilan Menu Menulis Huruf Hijaiyah

Gambar 12 berupa tampilan menulis huruf hijaiyah jika layar di sentuh untuk membuat huruf maka huruf yang di tulis akan terlihat

\section{Pengujian Sistem}

Berikut adalah tabel pengujian Black Box pada aplikasi pengenalan Huruf Hijaiyah dan Bahasa Arab.

Tabel 5. Blackbox testing

\begin{tabular}{|c|c|c|c|c|}
\hline No & Skenario & Test Case & $\begin{array}{c}\text { Hasil yang di } \\
\text { harapkan }\end{array}$ & Keterangan \\
\hline 1 & $\begin{array}{l}\text { Tampil } \\
\text { Menu } \\
\text { Utama }\end{array}$ & $\begin{array}{c}\text { Menampilkan } \\
\text { Halaman Menu } \\
\text { utama }\end{array}$ & $\begin{array}{c}\text { Tampil } \\
\text { Halaman Menu } \\
\text { Utama }\end{array}$ & Valid \\
\hline 2 & $\begin{array}{l}\text { Memilih } \\
\text { Menu } \\
\text { Belajar }\end{array}$ & $\begin{array}{c}\text { Menampilkan } \\
\text { Halaman Menu } \\
\text { Belajar }\end{array}$ & $\begin{array}{c}\text { Tampil } \\
\text { Kategori } \\
\text { Belajar }\end{array}$ & Valid \\
\hline 3 & $\begin{array}{l}\text { Memilih } \\
\text { Menu } \\
\text { Huruf } \\
\text { hijaiyah }\end{array}$ & $\begin{array}{l}\text { Menampilkan } \\
\text { halaman menu } \\
\text { Huruf Hijaiyah }\end{array}$ & $\begin{array}{c}\text { Tampil Huruf } \\
\text { Hijaiyah }\end{array}$ & Valid \\
\hline 4 & $\begin{array}{c}\text { Memilih } \\
\text { About }\end{array}$ & $\begin{array}{c}\text { Menampilkan } \\
\text { About }\end{array}$ & Tampil About & Valid \\
\hline
\end{tabular}

Pada tabel 5 pengujian dilakukan dengan mengunakan blackbox testing pada scenario nomer

- Sistem Akan Menampilkan Menu Utama kemudian dilakuan testcase menampilkan halaman menu utama hasilnya berupa tamoilan menu utama maka keteranganya valid sesuai dengan rencana
- Skenario memilih menu belajar maka dilakukan testcase menampilkan menu belajar, hasilnya tampil kategori belajar keteranganya valid sesuai dengan rencana

- Skenario memilih menu huruf hijaiyah maka dilakukan testcase menampilkan halan menu huruf hasil yang di harapkan valid sesuai rencana

- Skenario memilih about dilakukan taestcase menampilkan about hasilnya tampil about keterangan valid sesuai harapan

\section{Hasil}

Berdasarkan hasil uji blackbox testing maka dilakukan inplementasi pengujian kepada para responden yaitu terdiri dari 5 orang guru Paud Al Fina dan 10 orang siswa( pengisian di bawah pengawasan orang tua dan guru).

\section{TABEL 6. RESPONDEN}

\begin{tabular}{|c|c|c|c|}
\hline No & Pertanyaan & Ya & Tdk \\
\hline \multirow[b]{2}{*}{1} & Tingkat Kebutuhan pengguna: & \multirow[b]{2}{*}{15} & \multirow[b]{2}{*}{0} \\
\hline & $\begin{array}{l}\text { Apakah Aplikasi mengenal huruf hijaiyah } \\
\text { Sesuai Dengan Kebutuhan Pengguna ?.. }\end{array}$ & & \\
\hline \multirow[b]{2}{*}{2} & Tingkat Kecocokan & \multirow[b]{2}{*}{15} & \multirow[b]{2}{*}{0} \\
\hline & $\begin{array}{l}\text { Apakah Aplikasi mengenal huruf hijaiyah } \\
\text { Sesuai Tingkat Kecocokan dengan yang } \\
\text { diajarkan di sekolah }\end{array}$ & & \\
\hline \multirow[b]{2}{*}{3} & Tingkat kemudahan & \multirow[b]{2}{*}{15} & \multirow[b]{2}{*}{0} \\
\hline & $\begin{array}{l}\text { Apakah Aplikasi mengenal huruf hijaiyah } \\
\text { sangat mudah digunakan?... }\end{array}$ & & \\
\hline \multirow[b]{2}{*}{4} & Tingkat Motivasi & \multirow[b]{2}{*}{15} & \multirow[b]{2}{*}{0} \\
\hline & $\begin{array}{l}\text { Apakah anda termotifasi untuk menggunkan } \\
\text { Aplikasi mengenal huruf hijaiyah } \\
\text { berikutnya?... }\end{array}$ & & \\
\hline \multirow[b]{2}{*}{5} & Tingkat Kreatifitas & \multirow[b]{2}{*}{15} & \multirow[b]{2}{*}{0} \\
\hline & $\begin{array}{l}\text { Apakah Aplikasi mengenal huruf hijaiyah } \\
\text { membuat anda menjadi kreatif dan dapat } \\
\text { menyumbangkan saran dan Ide untuk } \\
\text { perbaikan aplikasi ini }\end{array}$ & & \\
\hline \multirow[b]{2}{*}{6} & Tingkat efektif & \multirow[b]{2}{*}{15} & \multirow[b]{2}{*}{0} \\
\hline & $\begin{array}{l}\text { Apakah aplikasi mengenal huruf hijaiyah } \\
\text { sangat efektif untuk belajar anak paud }\end{array}$ & & \\
\hline \multirow[b]{2}{*}{7} & Tingkat Ketertarikan & \multirow[b]{2}{*}{15} & \multirow[b]{2}{*}{0} \\
\hline & $\begin{array}{l}\text { anda tertarik untuk mengunakannya Aplikasi } \\
\text { mengenal huruf hijaiyah }\end{array}$ & & \\
\hline \multirow[b]{2}{*}{8} & Tingkat Kemudahan & \multirow[b]{2}{*}{15} & \multirow[b]{2}{*}{0} \\
\hline & $\begin{array}{l}\text { Apakah Aplikasi mengenal } \\
\text { hijaiyah.sangat mudah di gunakan }\end{array}$ & & \\
\hline \multirow[b]{2}{*}{9} & Tingkat Kesulitan & \multirow[b]{2}{*}{1} & \multirow[b]{2}{*}{14} \\
\hline & $\begin{array}{l}\text { Apakah Aplikasi mengenal huruf hijaiyah } \\
\text { sangat sulit untuk di gunakan }\end{array}$ & & \\
\hline \multirow[b]{2}{*}{10} & Tingkat Peminat & \multirow[b]{2}{*}{15} & \multirow[b]{2}{*}{0} \\
\hline & $\begin{array}{l}\text { Apakah anda Berminar mengunkan Aplikasi } \\
\text { mengenal huruf hijaiyah }\end{array}$ & & \\
\hline
\end{tabular}

Berdasarkan hasil tabel di atas dari 10 pernyataan bahwa penguna sebagian besar memilih Ya, dari Tingkat Kebutuhan pengguna 15 orang menjawab ya, Tingkat Kecocokan 15 orang menjawab ya, Tingkat kemudahan 15 orang menjawab ya, Tingkat Motivasi 15 orang menjawab ya, Tingkat Kreatifitas 15 orang menjawab ya, Tingkat efektif 15 orang menjawab ya, Tingkat Kemudahan 15 orang menjawab ya, Tingkat Kesulitan 
14 orang menjawab tidak dan 1 orang menjawab Ya, Tingkat Peminat 15 orang menjawab ya

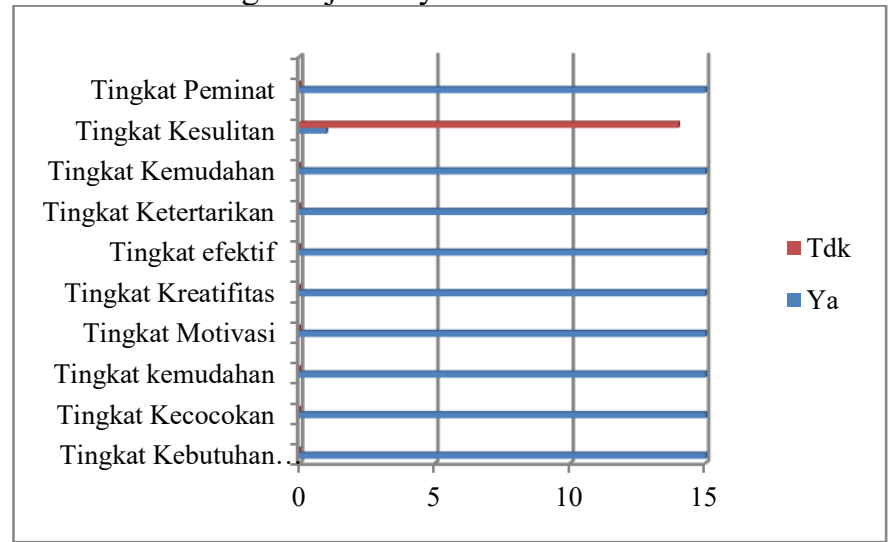

Gambar 13. grafik pernyataan responden

Dari gambar grafik 13 di atas dari semua tingkatan mayoritas menjawab ya, dan tingkat kesulitan mayoritas menjawab tidak dan itu berarti aplikasi ini mudah digunakan untuk paud al fina.

\section{KESIMPULAN}

Aplikasi pengenalan huruf hijaiyah berbasis android dapat di gunakan dengan mudah oleh siswa paud Al fina sehingga para siswa dapat belajar mengenal buruf ijahiyah kapan saja.

Aplikasi android dapat menampilkan detail menu utama agar mudah di gunakan. dapat menampilkan option menu belajar di mana berfokus pada menu dan jenis huruf hijaiyah itu sendiri dan konsep menulis huruf hijaiyah dalam aplikasi, selain itu menampilkan daftar huruf hijaiyah, serta dapat menampilkan gambar dan suara agar lebih menarik untuk anak.

Aplikasi mengenal huruf hijaiyah sangat efektif dan mudah di gunakan untuk siswa paud dalam mengenal dan menulis huruf hijaiyah

\section{REFERENCES}

[1] A. Kristanto, Perancangan Sistem Informasi, Revisi. Yogyakarta: Gaya Media, 2018.

[2] D. Sarbini, Nurtantyo, Riska, Efytra, Dian, Yuliana, Ariie WK "RANCANG BANGUN SISTEM INFORMASI AKADEMIK BERBASIS ANDROID," Dedikasi, vol. 15, no. Komputer, pp. 122-125, 2018.

[3] Z. Zahrotun, Lisna, Soleh, Ricky, "Mediapembelajaran Pengenalan Huruf Hijaiyahuntuk Anak Usia Dini 2-3 Tahun,” Telematika, vol. 12, no. Komputer, pp. 75-81, 2015.

[4] W. Yudhistira , R. J., \& Widiarina, "Animasi Interaktif Pengenalan Huruf Hijaiyah Berbasis Android," Tek. Komput., vol. V, no. Komputer, pp. 65-70, 2019, doi: 10.31294/jtk.v4i2.

[5] J. Yektyastuti, R., \& Ikhsan, "Pengembangan Media Pembelajaran Berbasis Android pada Materi Kelarutan untuk Meningkatkan Performa Akademik Peserta Didik SMA,” Inov. Pendidik. IPA, vol. 2, pp. 88-99, 2016, doi: http://dx.doi.org/10.21831/jipi.v2i1.10289.

[6] M. Muyaroah, Siti, Fajartia, "Pengembangan Media Pembelajaran Berbasis Android dengan menggunakan Aplikasi Adobe Flash CS 6 pada Mata Pelajaran Biologi," Innov. J. Curric. Educ. Technol., vol. 6, pp. 7983, 2017.

[7] sri marini, "Rancang Bangun Sistem Informasi Akademik Unisma Berbasis Android dan Web," Sinergi (seminar nasionall energi dan Teknol. 2016), pp. 112-117, 2016.

[8] M. dan R. A. . Shalahudin, Rekayasa Perangkat Lunak. Informatika, 2015.

[9] M. Efendi, Rusdi, Purwandari, Putri, Endina, Aziz, Abdul, "Aplikasi Pengenalan Huruf Hijaiyah Berbasis Marker Augmented Reality Pada Platform Android," pseudocode, vol. 2, no. komputer, pp. 124-134, 2015, doi: https://doi.org/10.33369/pseudocode.2.2.124-134.

[10] A. dan M. S. Rosa, Rekayasa Perangkat Lunak. Bandung: Informatika Bandung, 2013.

[11] S. S. H. Haqi Bay, Aplikasi Absensi Dosen dengan Java dan Smartphone sebagai Barcode Reader. Jakarta: PT Elex Media Komputindo, 2019.

[12] S. Handayani, "Perancangan Sistem Informasi Penjualan Berbasis ECommerce Studi Kasus Toko Kun Jakarta," J. Ilm. Vol., vol. 10, no. 2, p. 182, 2018, doi: 10.33096/ilkom.v10i2.310.182-189.

[13] M. K. Hidayat and R. C. P. Ningrum, "Sistem Informasi Penjualan Online Pada Toko Yusuf Bekasi,” J. Comput. Inf. Technol., vol. Vol.2 No.2, pp. 24-30, 2017.

[14] W. E. Fridayanthie, "Perancangan Sistem Informasi Penjualan Peralatan Hiking Berbasis Desktop Pada Toko Cimone Outdoor Tangerang," $J$. Khatulistiwa Inform., vol. 3, no. 2, pp. 143-151, 2015. 